\section{EMBRYRIDDLE}

Aeronautical University

SCHOLARLY COMMONS
International Journal of Aviation, Aeronautics, and Aerospace

\title{
Analysis of the ICAO USOAP Results in the Persian Gulf Region and its Relation to the Economic Indicators
}

Mohsen Ghahremani

Florida Institute of Technology, msnghahremani@gmail.com

Follow this and additional works at: https://commons.erau.edu/ijaaa

Part of the Aviation Safety and Security Commons

\section{Scholarly Commons Citation}

Ghahremani, M. (2020). Analysis of the ICAO USOAP Results in the Persian Gulf Region and its Relation to the Economic Indicators. International Journal of Aviation, Aeronautics, and Aerospace, 7(3).

https://doi.org/10.15394/ijaaa.2020.1505

This Article is brought to you for free and open access by the Journals at Scholarly Commons. It has been accepted for inclusion in International Journal of Aviation, Aeronautics, and Aerospace by an authorized administrator of Scholarly Commons. For more information, please contact commons@erau.edu. 


\section{Analysis of the ICAO USOAP Results in the Persian Gulf Region and its Relation to the Economic Indicators}

\section{Cover Page Footnote}

Aviation safety is one of the main ICAO's objectives, and ICAO is constantly trying to improve aviation safety in different ways. One of these ways is the monitoring of safety trends and indicators. ICAO audits the implementation of its Standard, Recommended Practices and Procedures through the Universal Safety Oversight Audit Program (USOAP). The purpose of this research was to analyze the results of the ICAO USOAP in the Persian Gulf region and to determine its relation with the economic conditions of the countries located in this region. The study based on correlational design and its approach to collecting and analyzing data was quantitative research. The archival data, which used in conducting this study, collected from reliable and accredited sources. The results of the analysis of the ICAO USOAP CMA scores in the Persian Gulf region indicate good improvement in the implementation of safety oversight systems. The average USOAP score in the Persian Gulf region was above the global average. Although countries: United Arab Emirates, Qatar, and Saudi Arabia have had the highest USOAP and economic indicators scores, the research couldn't find a strong positive relationship between the safety performance and economic development of the countries located in the Persian Gulf region. This study can be used by economists and aviation experts to interpret the interaction between the progress of the safety oversight system and the economic developments. It recommended, future research explores the relations between the improvement of the USOAP results and air traffic growth and determines how air traffic growth can affect the economy of a country.

This article is available in International Journal of Aviation, Aeronautics, and Aerospace: https://commons.erau.edu/ 


\section{Problem Statement}

The ICAO Member States use the USOAP results to determine the areas that they did not meet the targets outlined in the ICAO Global Aviation Safety Plan (GASP). The availability of USOAP CMA results in a transparent and relevant manner allows States to focus on areas of their safety oversight systems that need improvement (ICAO, 2018).

One of the objectives of USOAP is to ensure that ICAO SARPs implementation harmonized globally, thus all countries have the same access to the significant economic benefits of safe and reliable air transport. Insufficient information regarding the aviation safety oversight progress and the effects of safe air transportation on economic growth is a problem in most developing countries, especially if the industry is under governments' control. This study has sought to determine the interaction of the ICAO USOAP results, which present the safety oversight systems, and the economic development in the Persian Gulf region.

\section{Purpose Statement}

The purpose of this study was to assess the effective implementations (EI) of the critical elements (CE) of safety oversight systems regarding personnel licensing, aircraft operations, airworthiness of aircraft, aircraft accident and incident investigation, air navigation services, and aerodromes, in the Persian Gulf region and compare the results with the global average. It also explored the correlations between the ICAO USOAP results and the economic indicators used to measure the development of the countries in this region.

\section{Research Questions}

1. What are the results of ICAO USOAP in the Persian Gulf region comparing with the global average?

2. What are the correlations between the ICAO USOAP results and the economic indicators of the countries in the Persian Gulf region?

3.

\section{Literature Review}

Improving the safety of the global air transport system is ICAO's guiding and most fundamental strategic objective. The organization works constantly to address and enhance global aviation safety through the following coordinated activities and targets outlined in its Global Aviation Safety Plan (ICAO, 2019a, para.1). The Global Aviation Safety Plan (GASP) is ICAO's (2019b) top strategic safety document. The GASP, including the global aviation safety roadmap, serves as an action plan to assist the aviation community in achieving the objectives presented in the Plan, through a structured, common frame of reference for all relevant stakeholders. According to the 2017-2019 edition of the GASP, all States 
should reach an EI score of $60 \%$ for the eight CEs of a safety oversight system by the end of 2017.

Aviation safety is essential to ensure the development of the air transport sector. Air transport impacts tourism and trade. It serves as the main mode of transportation. It generates other socio-economic benefits which help eradicate poverty by creating jobs and enhancing air connectivity (ICAO, 2017).

USOAP CMA is a tool for monitoring the safety oversight capabilities and the safety performance of each country. Thus, any progress in the USOAP results improves safety oversight system of a country, and it causes to provide safe and reliable air transports services. On the other hand, a safe air transportation system may contribute to increased demand for air passengers and cargo traffic, and it will impact the economy in different ways such as providing direct, indirect and induced economic benefits.

\section{Economic Analysis of Aviation Safety}

While the worldwide aviation safety record has improved dramatically over time, these safety advances have not been evenly distributed across all segments of commercial aviation nor among all countries and regions of the world (Barnett, 2010). A few of researchers have tried to identify what the effects of aviation safety on the economical profitability of the industry.

The effect of profitability on an airline's safety record is one area that has received a fair amount of attention. Research performed in 1986 by Golbe found no significant relationship between airline profitability and safety. Rose (1990) found a significant relationship between profitability and lower accident rates. Upon a closer analysis of the data, it was determined that this correlation between profitability and safety was present for medium and small airlines but was not statistically significant for larger airlines. A 1997 analysis of the Canadian airline industry by Dionne, Gagné, Gagnon, and Vanasse (1997) identified a negative relationship between profitability and safety for the smallest airlines analyzed.

A recent update to the Rose analysis found a negative relationship between financial performance and accident rates among air carriers, especially among smaller regional carriers (Raghavan \& Rhoades, 2005). It was found that the negative relationship between profitability and safety existed for both major and regional airlines.

Noronha and Singal (2004) use a slightly different methodology to address the question whether an airlines' financial health has an impact on its safety record. The study showed that airlines with stronger bond ratings are safer than those airlines that are financially weak. The authors emphasize that although they found a correlation between financial health and airline safety, they were unable to establish causation.

Savage (2012) employed a different approach to determining if there is a link between an airline's finances and its safety record. In theory, an airline would 
think about safety as a quality indicator that would reduce the competitive focus on prices. In other words, by establishing a better safety record than its competitors, an airline should be able to increase its profitability.

The above are some studies that addressed the effect of aviation safety on profitability in the air transportation sector.

\section{Economic Analysis of Air Transportation}

There are two major types of studies evaluating the impact of air transportation. First, studies evaluating the direct, indirect and induced employment impact of air transportation which ignore the enabling effects. These studies are typically done for the developed economies because they use data-intensive regional input-output matrices which are rarely available for the developing countries (ICAO, 2004). Second, studies which attempt to evaluate the enabling impact of air transportation. The enabling impact of air transportation is defined as the total economic impact on employment and income generated by the economic activities which are dependent on the availability of air transportation services (ATAG, 2005).

The results of the study conducted by Ishutkina and Hansman (2009) showed that there is a correlation between air travel and GDP, however growth rates and the mechanisms behind the interaction differ for individual economies. Government plays an important role in this relationship since its policies can influence both economic and air transportation attributes through regulation and infrastructure investment.

In the book "Introduction to Air Transport Economics," the authorsstated the air transport industry is expected to grow significantly in regions where economies are developing. GDP and economic growth are strong leading indicators of the air transport industry's growth, so in the short term, these measures can be used to assess the industry (Vasigh, Fleming, \& Tacker, 2013).

\section{Economic Benefits of Air Transportation in Middle East}

Air transport supports 2.4 million jobs and $\$ 130$ billion in Middle East economic activity. Airlines, airport operators, retailers and other on-site businesses, as well as air navigation services and civil aircraft manufacturers, all contribute to GDP in the Middle East. In 2016, the operations of these businesses generated $\$ 32.9$ billion direct contribution to GDP. The aviation sector's spending with suppliers is estimated to have supported a further 389,500 jobs and a $\$ 20.9$ billion contribution to GDP. In addition, spending by those employed in the aviation sector and its supply chain supported 183,400 more jobs and a $\$ 9.8$ billion contribution to GDP ("Middle East: Aviation Benefits Beyond Borders," 2018).

\section{Middle East Benefits from Complying with ICAO Standards}

At the Fifth Meeting of Directors General of Civil Aviation for the ICAO Middle East Region (DGCA-MID/5) in Kuwait City on 8 November 2019, ICAO Secretary General Dr. Fang Liu underscored that the continued enhancement of the 
implementation of ICAO's safety, security, and sustainability standards and recommended practices (SARPs), strategies, and other initiatives, is unlocking tremendous economic and other sustainable development benefits in the region (Aviation.travel, 2019, ICAO, Para.1).

"The ICAO Middle East Region has been one of the fastest growing in the world for passenger and cargo traffic since 2011. Aviation presently supports more than 2.4 million jobs and contributes $\$ 130$ billion to GDP in MID Region GDP" (Liu, personal communication, November 8, 2019).

In summary, there are different points of view regarding the safety of air transportation and its economic benefits. One of the goals of this study was to identify and describe the correlation between economic indicators and the results of ICAO USOAP as an aviation safety index in the Persian Gulf region.

\section{Research Methodology}

The study based on correlational design, and it identified the relationship between the results of ICAO USOAP and the economic indicators that were selected to define the economic conditions of the countries in the Persian Gulf region. For creating the research design, the following measures have taken:

\section{The Type of Data}

For answering the research questions, it required to collect data regarding ICAO USOAP and the economic indicators in the Persian Gulf region. The original data collected from three main primary sources: the ICAO official website, the World Bank, and United Nations Development Programme (UNDP) websites.

\section{The Research Population and Sample}

As inferred from the research topic, the target population of this study was the ICAO State Members. As of April 2019, there are 193 ICAO members, which have adhered to the Chicago Convention on International Civil Aviation. In order to rationalize the global coordination structure and maximize available efficiencies, the ICAO regional offices were established (ICAO, About ICAO, para.2). Right now, ICAO has six regional offices all around the world.

The ICAO MID Office was established in Cairo, Egypt, in 1953 and encompasses 15 member States. ICAO MID Office tries to handle the challenges in this region with a goal to provide the highest level of safety, security, efficiency and to achieve a sustainable and environment-friendly growth of international civil aviation (ICAO, "Middle East Regional Office", para.1 \& para.5). The sample population of the study was a part of ICAO Middle East States which geographically located in the Persian Gulf region includes Bahrain, Iran, Iraq, Kuwait, Oman, Qatar, Saudi Arabia, and the United Arab Emirates.

\section{The Variables}

The variables present the attributes of the study. Since this study was correlational research, the terms "dependent" and "independent" didn't apply 
because no controlled experiment has performed. There were two variables for this study: the results of ICAO USOAP and the economic indicators in the Persian Gulf region.

\section{The Method for collecting and Analyzing Data}

One of the most common data collection methods for correlational research is using archival data. The study's approach to collecting and analyzing data was quantitative research, and the results expressed in numbers and graphs. The data analysis is the final step in designing the research and describes how the study data is analyzed. For doing this, first, the quantitative collected data regarding the EIs of CEs in each audit area and the economic indicators of the countries were analyzed and the results reported in the appropriate charts and tables which they were easier for understanding. Second, correlation analysis used to explore the relationships between the ICAO USOAP results and the economic indicators. This study employed the Pearson correlation, which is one of the most popular forms of correlation analysis. Excel application was used to calculate the average scores and the Pearson correlations too. All the displayed results based on the findings of the statistical analyses. The results of the statistical analyses used to answer the research questions.

\section{Results of the Study}

The results of the study describe in three main sections: The analysis of ICAO USOAP Results, The analysis of Economic Indicators, and The Correlation Analysis. The ICAO USOAP Results section reports the EIs of CEs in the eight audit areas. It also compares the USOAP scores in the Persian Gulf region with the global average. The Economic Indicators section includes analysis of five indicators, which are used to determine the economic development of countries. The Correlation Analysis section employed the scatter charts and Pearson coefficient correlations to show the relationships between the ICAO USOAP results and the economic indicators.

\section{The analysis of ICAO USOAP Results}

This research provides the results and analysis of data from activities conducted within the Universal Safety Oversight Audit Program Continuous Monitoring Approach (USOAP CMA) in the Persian Gulf region. There are eight countries in this region that all were audited by ICAO, except Iraq. Table 1 shows the date of the latest ICAO safety audits in these countries. 
Table 1

The Date of the Latest ICAO Safety Audits in the Persian Gulf Region

\begin{tabular}{cccccccc}
\hline & \multicolumn{8}{c}{ Name of Country } \\
\hline & Bahrain & Iran & Kuwait & Oman & Qatar & Saudi & The \\
Year & 2018 & 2018 & 2017 & 2013 & 2018 & 2014 & 2015 \\
\hline
\end{tabular}

Note. The data in table 1 was retrieved from ICAO Website (https://www.icao.int)

An in-depth analysis of the USOAP-CMA data could be very useful for the identification of areas of concern, common deficiencies, etc. and would provide good insight for the prioritization of Corrective Action Plan for each country. The research was carried out an analysis in the eight audit areas as the followings:

\section{Primary Aviation Legislation and Civil Aviation Regulations (LEG)}

Based on the analyzed data, the average of effective implementation (EI) in the LEG area in the Persian Gulf Region is $81.69 \%$ which is higher than the global average $(74.81 \%)$. If the $60 \%$ EI target is applied to individual audit areas, then one country (Oman) needs to further improve in the LEG implementation.

\section{Civil Aviation Organization (ORG)}

The result of the analyzed data shows the average of EI in the ORG area in the Persian Gulf Region is 81.54\%, which is higher than the global average $(71.72 \%)$. If the $60 \%$ EI target is applied to each audit area, then two countries (Bahrain and Oman) need to further improve implementation in the ORG area.

\section{Personnel Licensing and Training (PEL)}

By drilling down in the PEL audit area in the Persian Gulf Region, it clarifies all countries in the region have met the $60 \%$ targeted EI. Based on the analyzed data, the average of EI in the PEL area in the Persian Gulf Region is $89.63 \%$ that it is higher than the global average $(74.92 \%)$.

\section{Aircraft Operations (OPS)}

According to the fifth meeting of ICAO MID Safety Support Team Report and by drilling down in the OPS audit area, it clarifies all countries in the Persian Gulf region have met the $60 \%$ targeted EI in the OPS area. The analyzed data indicates the average of effective implementation (EI) of the OPS requirements in the Persian Gulf Region is $86.79 \%$ that it is higher than the global average (71.44\%).

\section{Airworthiness of Aircraft (AIR)}

By drilling down in the AIR audit area in the Persian Gulf Region, it clarifies all countries in this region have met the $60 \%$ targeted EI. The average EI of the AIR in the Persian Gulf Region is $93.10 \%$ and all countries in the AIR audit area are above the global average (80.29\%).

\section{Aircraft Accident and Incident Investigation (AIG)}

The result of the analyzed data shows the average of EI in the AIG audit area in the Persian Gulf Region is $74.18 \%$, which is higher than the global average 
(57.31\%). If the 60\% EI target is applied to individual audit areas, then two countries (Kuwait and Oman) need to further improve implementation in the AIG area.

\section{Air Navigation Services (ANS)}

The results of effective implementations (EI) of the ANS audit area in the Persian Gulf countries indicate all countries in this region have met the $60 \%$ targeted EI. The regional average effective implementation of the ANS is $84.85 \%$ and all countries in this area except Oman are above the global average (63.49\%).

\section{Aerodromes and Ground Aids (AGA)}

According to the fifth meeting of ICAO MID Safety Support Team Report and by investigating in the AGA audit area, it clarifies all countries in this region have met the $60 \%$ targeted EI. Based on the analyzed data, the average effective implementation (EI) of the AGA requirements in the Persian Gulf Region is $82.35 \%$, which is higher than the global average $(62.39 \%)$.

The Average of Effective Implementations

Figure 1 presents the average of EI of the CEs in the eight audit areas in the Persian Gulf Region. The results of ICAO USOAP CMA show the United Arab Emirates has the highest average of EIs $(99.31 \%)$ and Qatar, with the average score of $90.73 \%$ placed in the second and it is followed by Saudi Arabia, with the average score of 89.58 .

\section{Figure 1}

The average of EI of CEs in the eight audit areas in the Persian Gulf Region

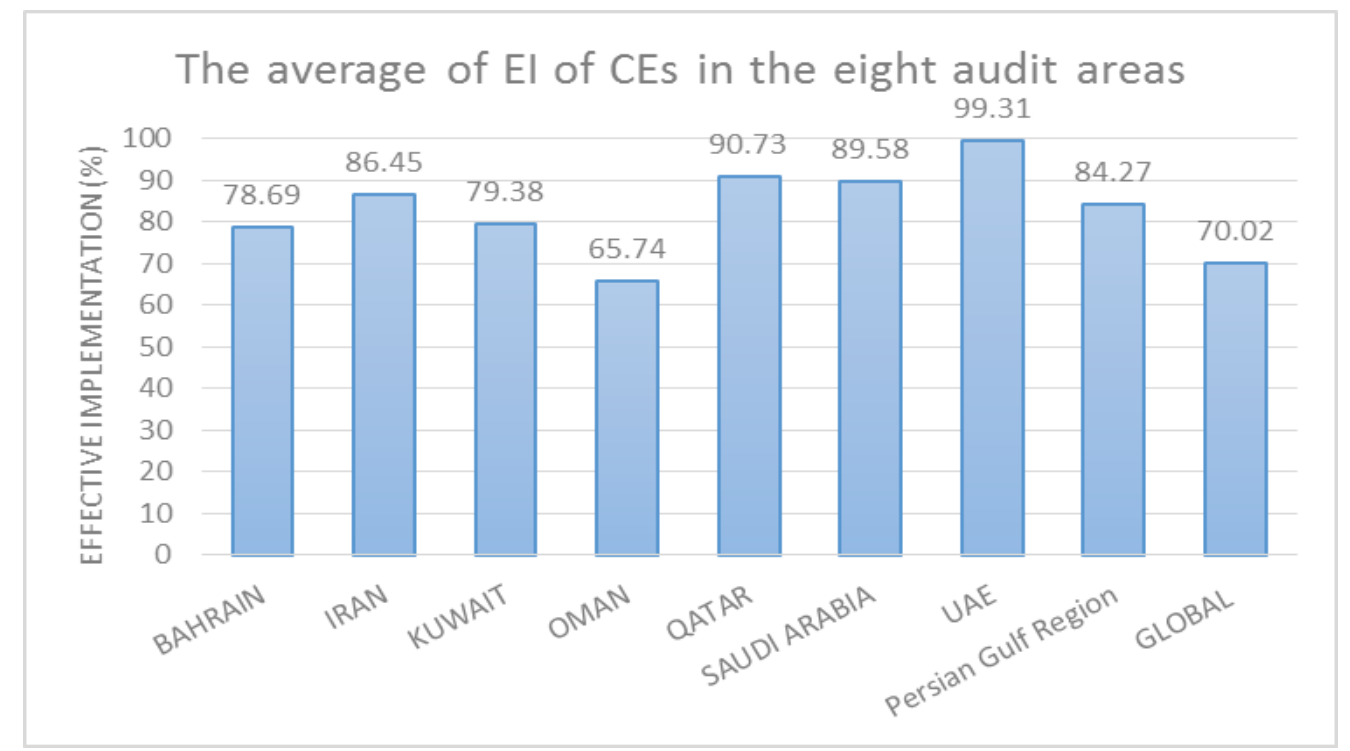

Note. Source ICAO iSTARS dated March 2020. 
Figure 1 shows the average EI of CEs in the Persian Gulf region (84.27\%) is higher than the global average. Almost all the countries in this Region (except Oman) have the average USOAP score above the global average.

\section{The Analysis of Economic Indicators}

In this study, aviation safety has analyzed in two parts: Technically, which is related to the ICAO USOAP results, and economically, which linked to the economic indicators of the countries located in the Persian Gulf region and its relation to the USOAP results. The five major economic factors selected to analyze in the Persian Gulf region are the followings:

\section{Population}

The population of a country and its economic growth is closely interlinked with the attainment of economic development (MBA Knowledge Base, The Importance of Population Trends in Business, para.2). According to the data, Iran with $82,360,000$ people has the most and Bahrain with 1,569,439 people has the least population in this region in 2018.

\section{Gross Domestic Product (GDP)}

The measurement of GDP is used to calculate the living standards in a country. The relationship between GDP and economic growth is the fact that GDP serves as a mean for analyzing how an economy is behaving (Ejim, 2020). The data shows Saudi Arabia with $\$ 786,522 \mathrm{M}$ has the highest and Bahrain with $\$ 37,746 \mathrm{M}$ has the lowest GDP in the region in 2018.

\section{GDP per capita}

GDP per Capita is used to determine personal income, adjusted for inflation with real GDP and adjusted for purchasing power parity to control for the impacts of regional price disparities (Hall, 2018). Based on gathered data, Qatar with $\$ 68,794$ has the highest and Iran with $\$ 5,514$ has the lowest GDP per Capita in the Persian Gulf region in 2018.

\section{Gross National Income (GNI) per capita}

GNI per capita is widely regarded as a good indicator of the general standard of living in a country, and it is a good starting point for giving an idea of the extent of global inequalities between countries (Thompson, 2017). According to the UNDP, Qatar with $\$ 110,489$ has the highest and Iran with $\$ 18,166$ has the lowest GNI per capita in the region in 2019.

\section{Human Development Index (HDI)}

Many economists and academics have observed that income is not the only determinant of well-being, so other metrics have been proposed to measure the standard of living (Hall, 2018). HDI is the index used by the United Nations to measure the progress of a country based on human development. HDI is ranked on a scale from 0 to 1.0 , with 1.0 being the highest human development. According to the UNDP, the UAE with a score of 0.866 has the highest and Iran with a score of 0.797 has the lowest HDI in the region. 


\section{The Correlation Analysis}

There are several types of correlation coefficients, but in this study, Pearson's correlation employed to explore the relationships between the safety oversight systems and economic indicators used to measure development of the countries located in the Persian Gulf region (Table 2).

Table 2

The Pearson's Correlation Between the USOAP Results and the Economic Indicators in the Persian Gulf Region

USOAP Results

\begin{tabular}{lcc} 
Pearson's correlation & Coefficient $(\mathbf{r})$ & Correlation \\
\cline { 2 - 3 } Population & 0.21 & positive very weak \\
GDP per capita & 0.43 & positive weak \\
GNI per capita & 0.39 & positive weak \\
HDI & 0.54 & positive moderate
\end{tabular}

This study also discussed the correlations between the chosen economic indicators. Pearson's Correlation Coefficient between the population and GDP per capita of the countries in the Persian Gulf region $r=-0.61$, which shows a negative moderate correlation. There is a strong positive correlation $(r=0.98)$ between the GDP per capita and GNI per capita in the region. Pearson's Correlation Coefficient between the HDI and GDP per capita $\mathrm{r}=0.59$ and the Coefficient between the HDI and GNI per capita, $r=0.49$ show positive moderate correlations.

\section{Conclusions}

The results of the research and analysis of the ICAO USOAP CMA scores in the Persian Gulf region from 2013 to 2020 indicates a good improvement in the implementation of safety oversight systems. Figure 2 shows the average of USOAP score for the States in the ICAO MID region in 2018. By comparing this picture with Figure 3, it is noticed good progress in EIs in the Persian Gulf region. Among the countries in this region, Qatar has a huge improvement in its score and moved from ranking 10 to 2 in the MID region in less than two years.

\section{Figure 2}


The average of USOAP score for the States in the ICAO MID region in 2018 Note. This figure was reprinted from ICAO MID Safety Support Team - Fifth

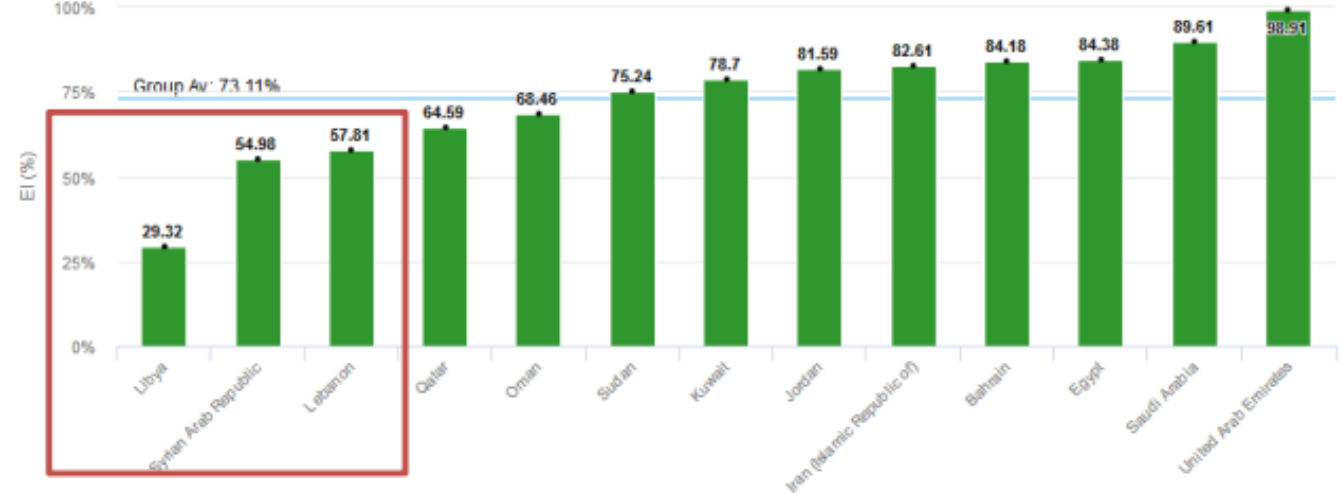

Meeting (MID-SST/5) Report, Cairo, Egypt, February 2019.

Although the current average USOAP score in the Persian Gulf region $(84.27 \%)$ is higher than what it was in 2018 , the score of some countries like Bahrain decreased and some countries like Iran and Kuwait despite small improvements in EIs, their position has not changed on the list since 2018. However, at the time of writing the paper, the average USOAP score in the Persian Gulf region is above the global average (Figure 3).

\section{Figure 3}

The average of USOAP score for the States in the Persian Gulf region in 2020 Note. Source ICAO iSTARS dated March 2020.

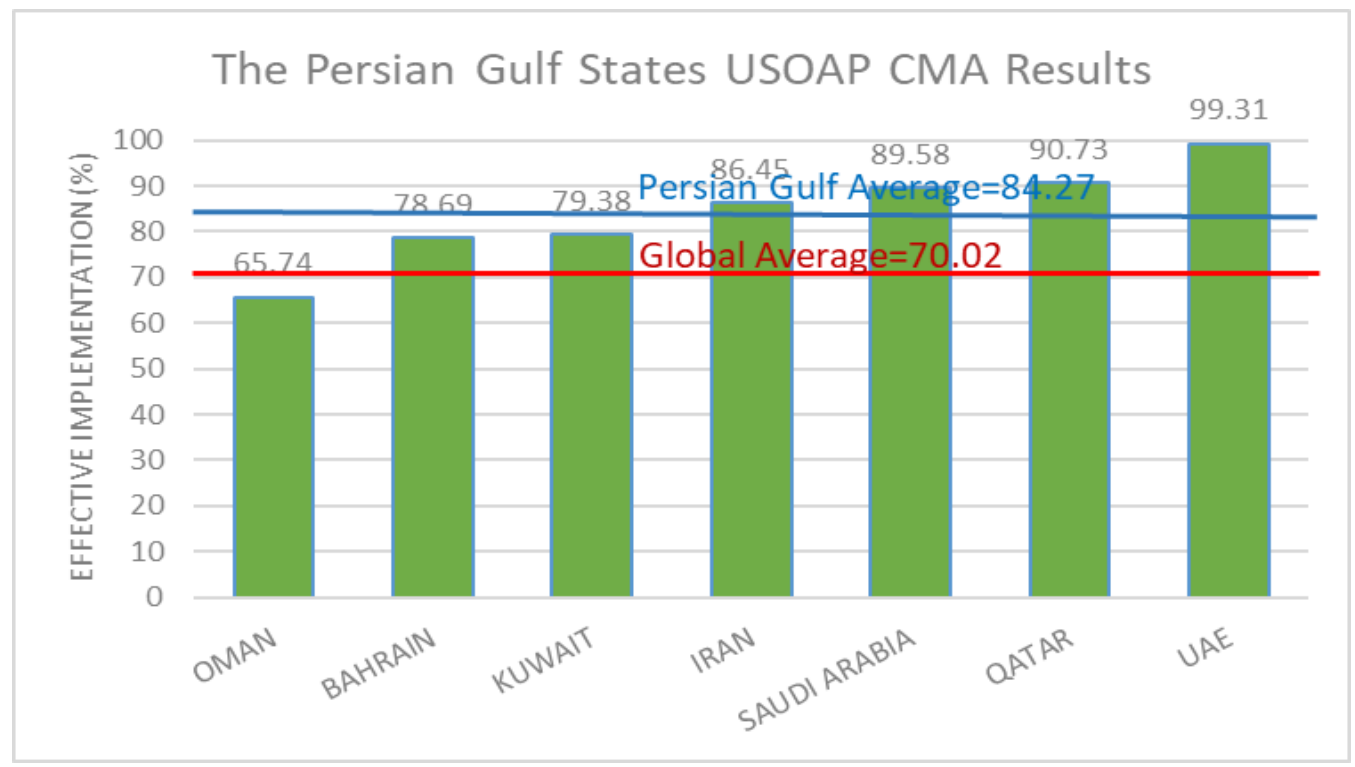


As stated, Iraq is the only country that has not yet received a USOAP audit in the Persian Gulf region. All countries in this region have achieved the 60\% EI, as suggested by the Global Aviation Safety Plan (GASP). despite Oman has met the targeted EI, it still needs some improvement to reach the global and regional averages.

The Persian Gulf has one of the world's largest energy sources of oil and gas and supplies the energy to most of the industrialized countries. Thus, the economy of the countries located in this region is mainly based on selling oil and gas. The results of economic indicators analysis present the population and GDP positively interacted in most countries. So, whatever a country's population is more, its GDP is higher accordingly. On the other hand, the GDP per capita and GNI per capita show a positive strong correlation with each other and a negative relation with the population. If the HDI is one of the main factors in determining economic development and by considering the other indicators, the results of economic analysis indicate that the UAE, Saudi Arabia, and Qatar have better economic conditions than the countries in the region.

According to the Industry High Level Group (IHLG) report, the Middle East has been the fastest growing region for passenger and cargo traffic since 2011. This increase of air traffic could cause growth in the economic output and jobs in the region in the next decade. The growth of air traffic depends on various factors such as airfares, relative prices, real income, level of output, etc. Although there is not a clear understanding of how safety performance affects air traffic demand, public safety reputation might affect travelers' choice of destinations and airlines. Accidents and incidents might lead to an immediate decline in demand to travel with a particular airline. On the other hand, a potential impact of safety on traffic demand can be estimated using the econometric model, which uses an effective implementation (EI) score measured by the ICAO Universal Safety Oversight Audit Programme Continuous Monitoring Approach (USOAP CMA) as a proxy to each State's safety performance (IHLG, 2017).

Since the results of correlation analysis indicate the HDI, among the other economic indicators, has had the most correlation with the USOAP scores, it was selected as an indicator to compare the economic conditions with the safety oversight systems in the Persian Gulf region. Based on the information of the correlation analysis, the three countries: the UAE, Qatar, and Saudi Arabia have had the highest USOAP and HDI scores. It shows their development in aviation safety and economic performance. On the other hand, Iran placed on ranking four in implementing the ICAO SARPs, but the country's economic condition was the worst in the region. Oman and Bahrain were at the bottom lines on the USOAP ranking, although their DHI ranking placed in the middle of the list.

In summary, this research couldn't find a strong positive relationship between safety oversight systems and economic development of the countries 
located in the Persian Gulf region, but according to the ICAO, 10 percent improvement of the EI of a State's safety oversight system might generate, on average, an additional 1.8 percent of aircraft departures from the State concerned (IHLG, 2017). It means an improvement in the safety performance of a country may contribute to the air traffic growth and leads to the economic development of the country.

\section{Recommendations}

Based on the results of this study, the first recommendation is to the countries in the Persian Gulf region which didn't get good results in the USOAP and economic performance. It is required to work on the issues highlighted in the study findings. The second recommendation is to researchers regarding data collection in archival research. Since in archival research, they have no control over how the data was collected, so it is very important to collect data from reliable and accredited sources. The third recommendation is to the ICAO. If the research requires more technical details about the data collected on the ICAO website, ICAO should provide access for researchers and helps for the enrichment of the research.

The last set of recommendations are for future research. The scope of this research limited to investigate the results of ICAO USOAP in the eight audit areas in seven countries in the Persian Gulf region. The study analyzed the collected data, not interpret the results. Future research could interpret the results of this study. As stated, Qatar has got tremendous progress in EIs of ICAO USOAP, thus its arrangements for reaching the EIs above $90 \%$ could be a good case study for future research on how the progress achieved. According to the ICAO, improvement of the EI of safety oversight systems might contribute to the air traffic growth, and the result might lead to economic development in a country. Future research could work on this theory; explore the relationships between the improvement of the EI and air traffic growth, and determine how the air traffic growth can affect the economy of a country. 


\section{References}

Air Transport Action Group. (2005, October). The economic and social benefits of air transport. Retrieved from: https://www.icao.int/

Aviation Benefits Beyond Borders. (2018). Middle East. Retrieved from: https://aviationbenefits.org/

Aviation.travel. (2019, November 13). ICAO: Middle East one of the fastest growing regions for air traffic. Retrieved from: https://aviation.travel/

Barnett, A. I. (2010). Cross-national differences in aviation safety records. Transportation Science, 44(3), 322e332.

Dionne, G., Gagné, R., Gagnon, F., \& Vanasse, C. (1997). Debt, moral hazard and airline safety. An empirical evidence. Retrieved from https://www.researchgate.net/publication/5182024_Debt_moral_hazard_a nd_airline_safety_An_empirical_evidence

Ejim, E. (2020, February 21). What Is the relationship between GDP and economic growth? Retrieved from: https://www.wisegeek.com/

Golbe, D. (1986). Safety and profits in the airline industry. The Journal of Industrial Economics, 34(3), 305-318.

Hall, M. (2018, June 11). How does GDP affect the standard of living? Retrieved from: https://www.investopedia.com/

Industry High Level Group (IHLG). (2017). Aviation benefits. Retrieved from: https://www.icao.int/

ICAO. (2004). Economic contribution of civil aviation. Volume 1. Retrieved from: https://www.icao.int/

ICAO. (2017). Doc9734: Safety oversight manual part A - The establishment and management of a state safety oversight system (3rd ed.). Retrieved from https://www.icao.int/

ICAO. (2018). Safety report- A coordinated, risk-based approach to improving global aviation safety. Retrieved from: https://www.icao.int/

ICAO. (2019a). Universal safety oversight audit programme-continuous monitoring approach results- SAFETY REPORT; 1 January 2016 to 31

December 2018. Retrieved from: https://www.icao.int/

ICAO. (2019b, February 21). USOAP aircraft operations and AGA areas-data analysis report. Fifth Meeting (MID-SST/5). Cairo, Egypt.

Ishutkina, M., \& Hansman, J. (2009, March). Analysis of interaction between air transportation and economic activity. Retrieved from: https://core.ac.uk/

MBA Knowledge Base. (2010). The importance of population trends in business. Retrieved from: https://www.mbaknol.com/

Noronha, G., \& Singal, V. (2004). Financial health and airline safety. Managerial and Decision Economics, 25(1), 1e16. 
Oster, C. V., Strong, J. S., \& Zorn, C. K. (March 2010). Why airplanes crash: causes of accidents worldwide. Arlington, VA.

Raghavan, S., \& Rhoades, D. L. (2005). Revisiting the relationship between profitability and air carrier safety in the US airline industry. Journal of Air Transport Management, 11, 283-290.

Rose, N. L. (1990). Profitability and product quality: Economic determinants of airline safety performance. Journal of Political Economy, 98, 944-964.

Savage, I. (1999). Aviation deregulation and safety in the United States: The evidence after twenty years. Retrieved from https://faculty.wcas.northwestern.edu/ ipsavage/204-manuscript.pdf

Thompson, k. (2017, January 30). Economic indicators of development. Retrieved from: https://revisesociology.com/

Vasigh, B. Fleming, K \& Tacker, T. (2013). Introduction to air transport economics: From theory to applications $\left(2^{\text {nd }}\right.$ ed.). New York: Routledge. 